\title{
EFFECT OF SPIN STABILIZATION ON FINAL STAGE ROCKET FOR DIFFERENT CROSS WIND CONDITIONS IN MARS ATMOSPHERE
}

\author{
MANIKANDAN. $\mathbf{S}^{1^{*}}$, SARATHKUMAR SEBASTIN. $\mathbf{J}^{2} \&$ DHANAJAYAN. $\mathbf{M}^{3}$ \\ School of Mechanical Engineering, Lovely Professional University, Phagwara, Punjab, India
}

School of Mechanical Engineering, Kalasalingam Academy of Research and Education, Virudhunagar, Tamilnadu, India

\begin{abstract}
Space Shuttle which planned or Mars mission usually deigned with multi-stages. The shape of the final stage is almost "Cone". In order to stabilize the final stage inside the Mars atmosphere, we have to employ certain stabilization technique. In these paper, we discuss spin stabilization to stabilize the final stage rocket and finding the RPM for which "No side force" acts on the final stage. Finally, we compare results of same final stage stabilization in Earth and Mars atmosphere
\end{abstract}

KEYWORDS: Mars atmosphere, Side force, Spin Stabilization, Upper stage rocket

Received: Jun 09, 2020; Accepted: Jun 29, 2020; Published: Aug 14, 2020; Paper Id.: IJMPERDJUN2020771

\section{INTRODUCTION}

To make scientific research on Mars planet, we send multi-stage rocket with payload which can examine minerals, atmospheric properties and Human living possibilities. Mars atmosphere contains $95.32 \%$ Carbon dioxide, $2.6 \%$ nitrogen and $1.9 \%$ argon. To avoid atmosphere disturbance and keep the final stage on correct flight path, the final stage can be stabilized Spin about its longitudinal axis. Cross-wind direction considered in this paper is normal to the Longitudinal axis. Flight velocity considered in this paper is $50 \mathrm{~m} / \mathrm{s}$ and crosswind velocity as $5 \mathrm{~m} / \mathrm{s}$ and $15 \mathrm{~m} / \mathrm{s}$. we found RPM of stabilized path for above two conditions

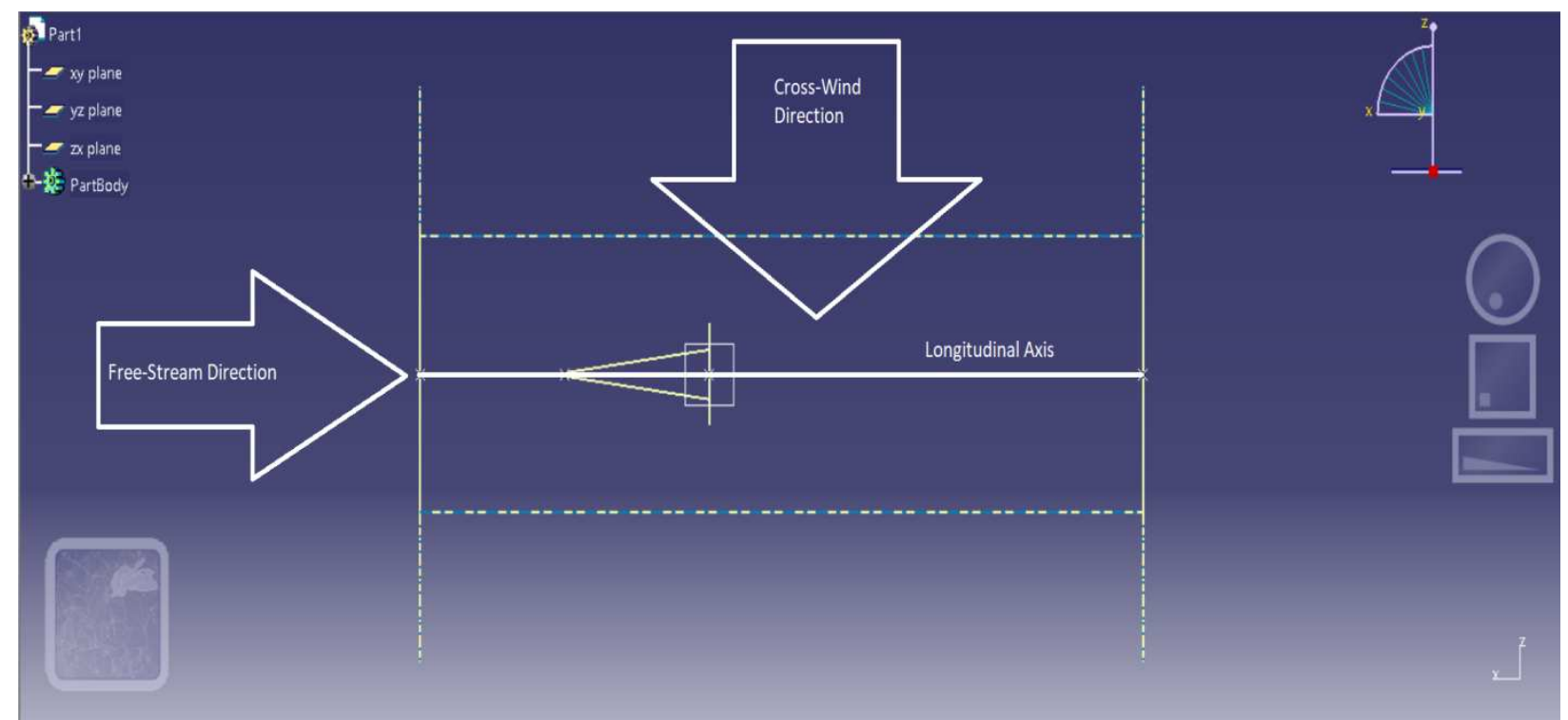

Figure 1: Normal Crosswind and Free Stream Direction with respect to final stage rocket in XYZ Coordinate System 


\section{METHODS}

We have used 2 linear velocities and 1 angular velocity in this paper. Linear velocities are flight velocity and crosswind velocity. Angular velocity is RPM of the missile. By keeping the both linear velocity constant and changing the RPM, we will get different side forces for different RPM. Plotting the side forces for different RPM, we will get Zero side force for the particular RPM. That RPM is stabilized one for respective flight velocity and crosswind velocity.

\section{DESIGN}

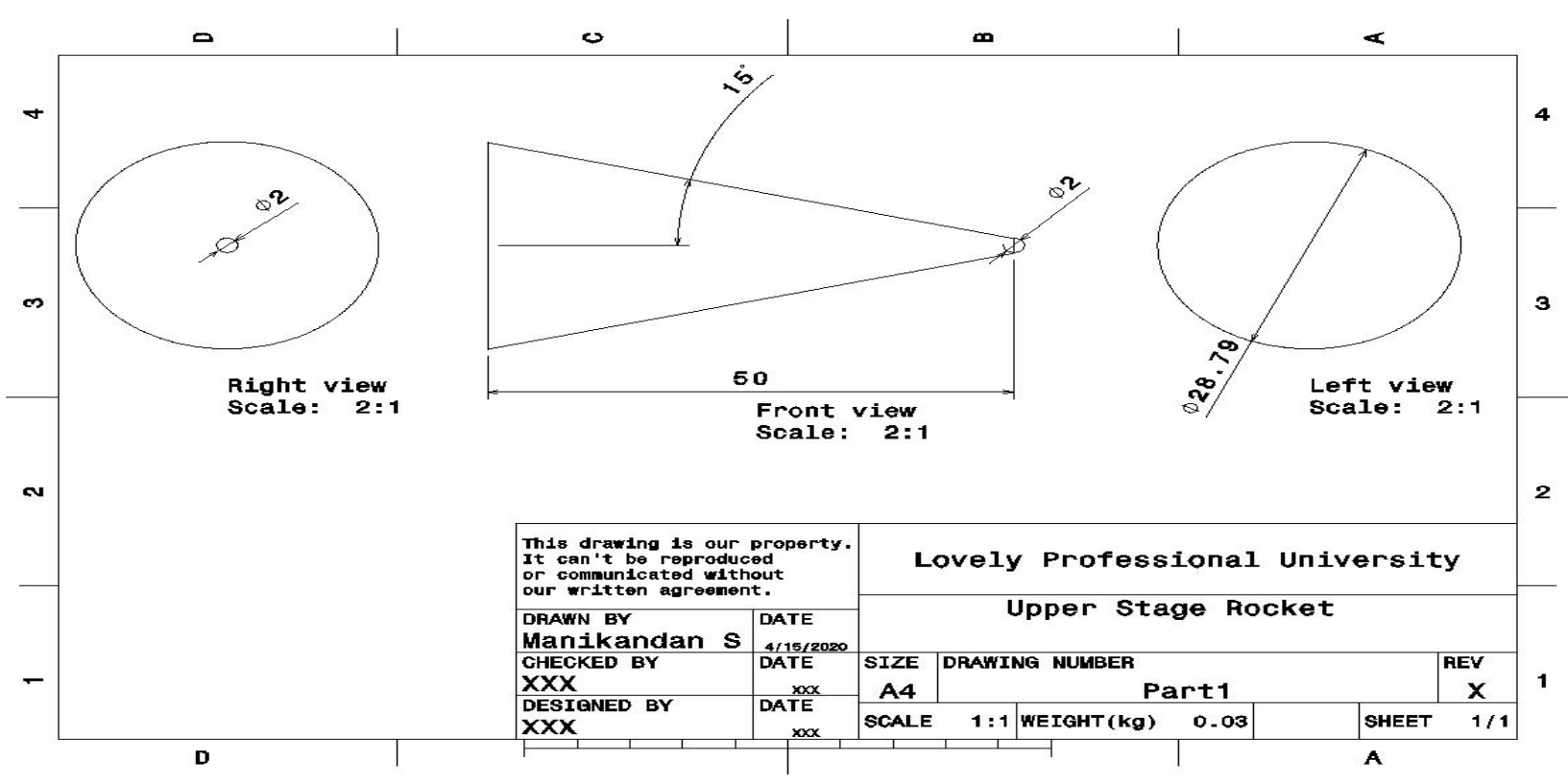

Figure 2: Final Stage Rocket with Dimension

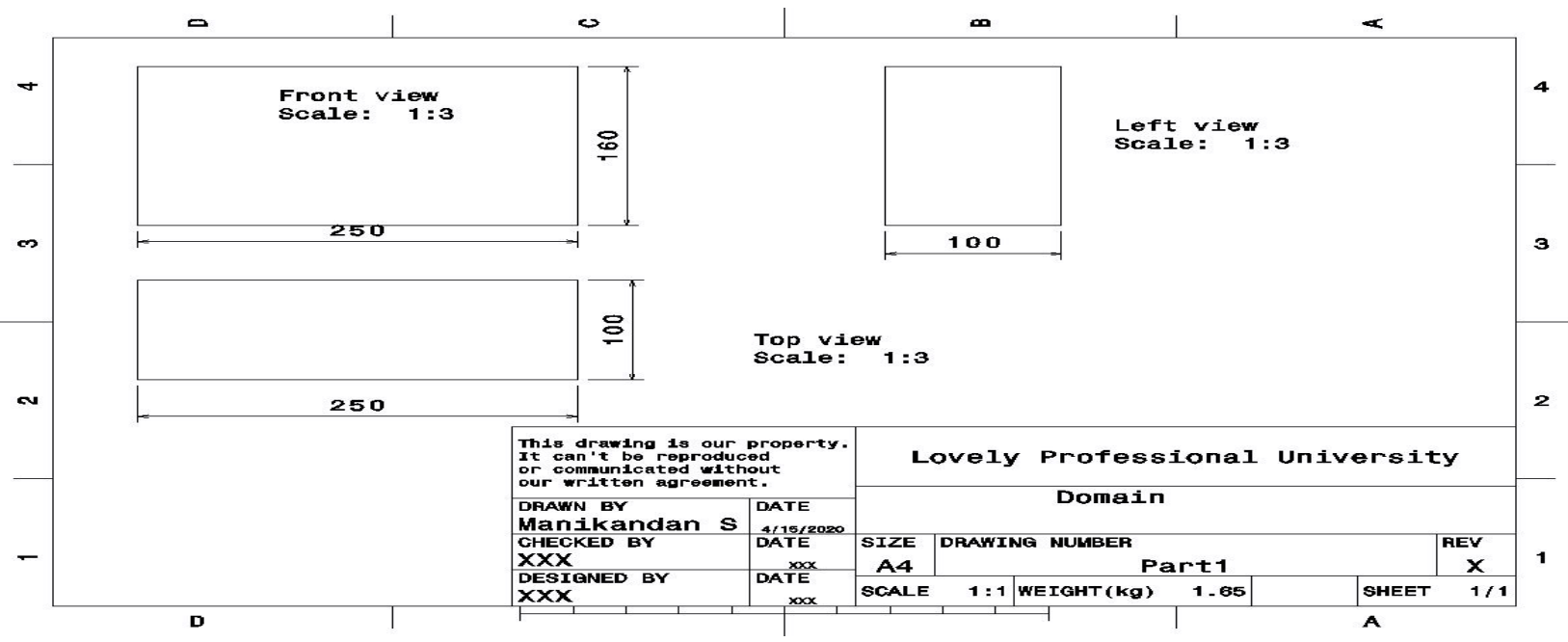

Figure 3: Domain Dimension 


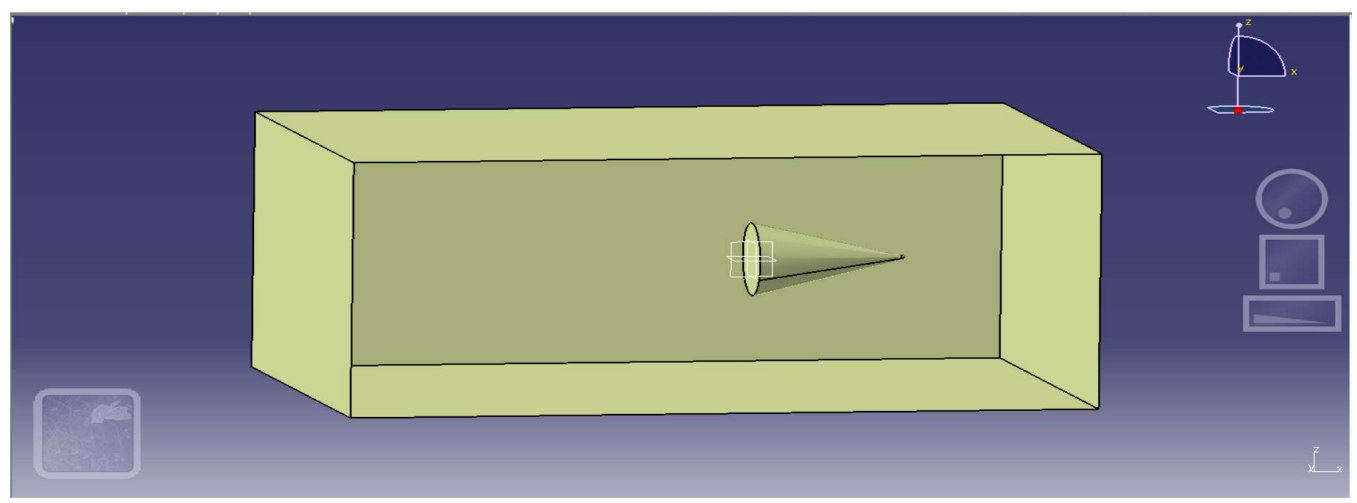

Figure 4: Final stage rocket with Domain

\section{INTRODUCTION TO CFD}

Meshing is done in ICEM CFD. ANSYS CFX will be appropriate for rotating component since Final stage rocket is spinning.

1. Type: Flow Analysis

2. Software Package: $\quad$ ANSYS 16.1

a. Meshing: $\quad$ ICEM-CFD 16.1

b. Pre-processing: CFX-Pre 16.1

c. Solver: $\quad$ CFX-Solver 16.1

d. Post-Processing: CFD-Post 16.1

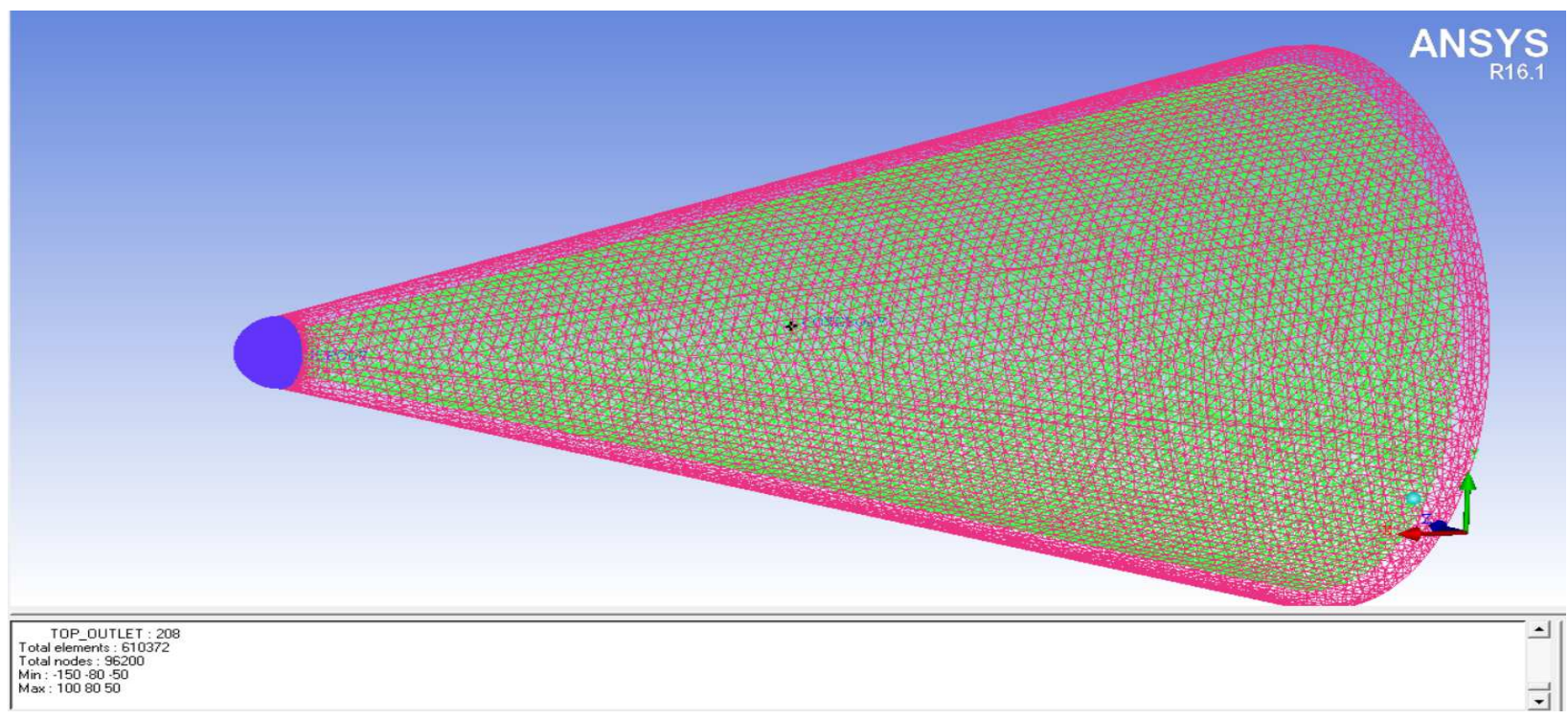

Figure 5: Meshing of Fluid 1 Domain and Final Stage Rocket 


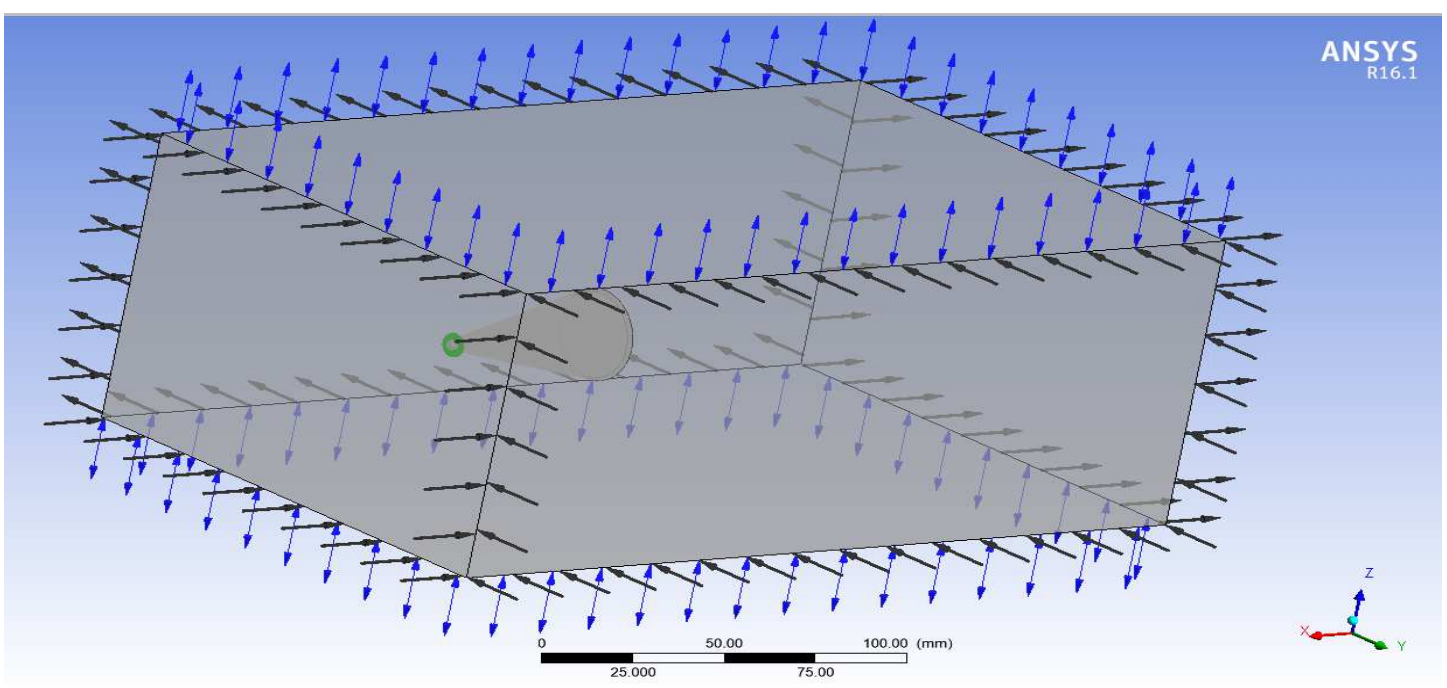

Figure 6: Final Stage Rocket with complete domain and Boundary Condition

Note: Black Arrows represents inlet and outlet Boundary condition and blue arrow represents opening boundary condition

SOLVER: Steady state analysis with 1000 iteration

\section{RESULTS}

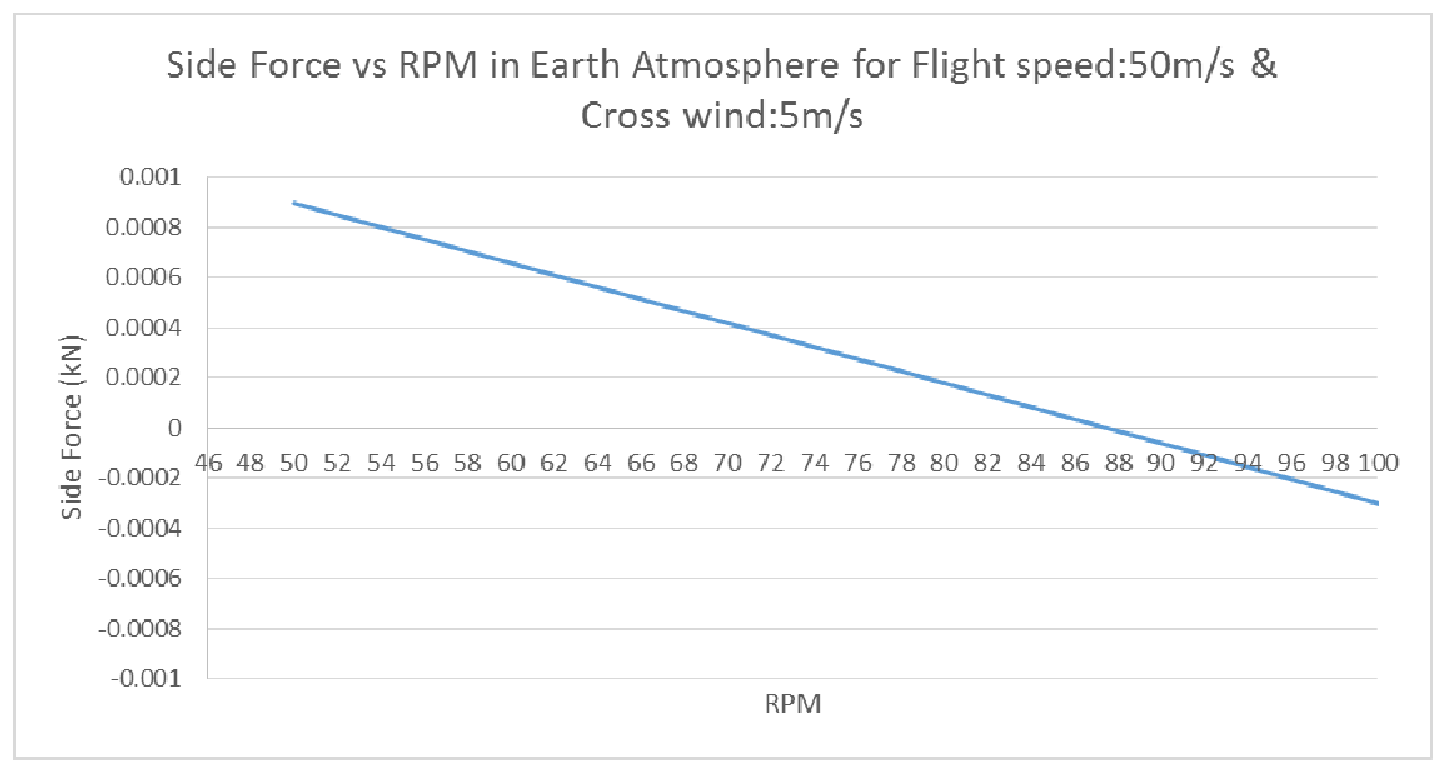

Graph 1: Side Force vs RPM of Final stage rocket in Earth Atmosphere for Flight speed:50m/s \& Cross wind:5m/s

Note: Positive RPM denotes clockwise rotation and Negative RPM denotes Anti-clockwise about positive X-axis. Value of side force becomes "zero" at RPM 88 (Clockwise) 


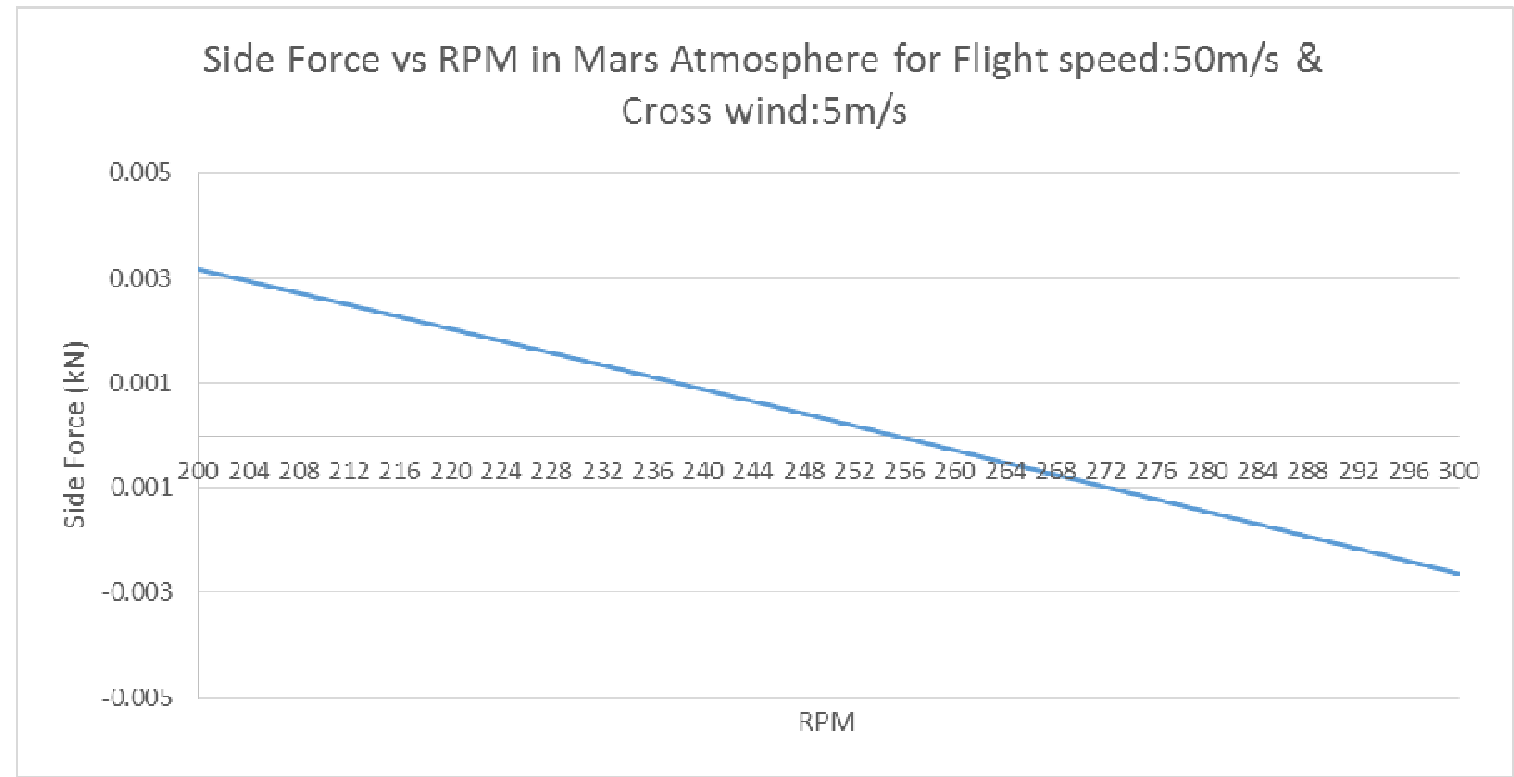

Graph 2: Side Force vs RPM of Final stage rocket in Mars Atmosphere for Flight speed:50m/s \& Cross wind:5m/s

Note: Positive RPM denotes clockwise rotation and Negative RPM denotes Anti-clockwise about positive X-axis. Value of side force becomes "zero" at RPM 256 (Clockwise)

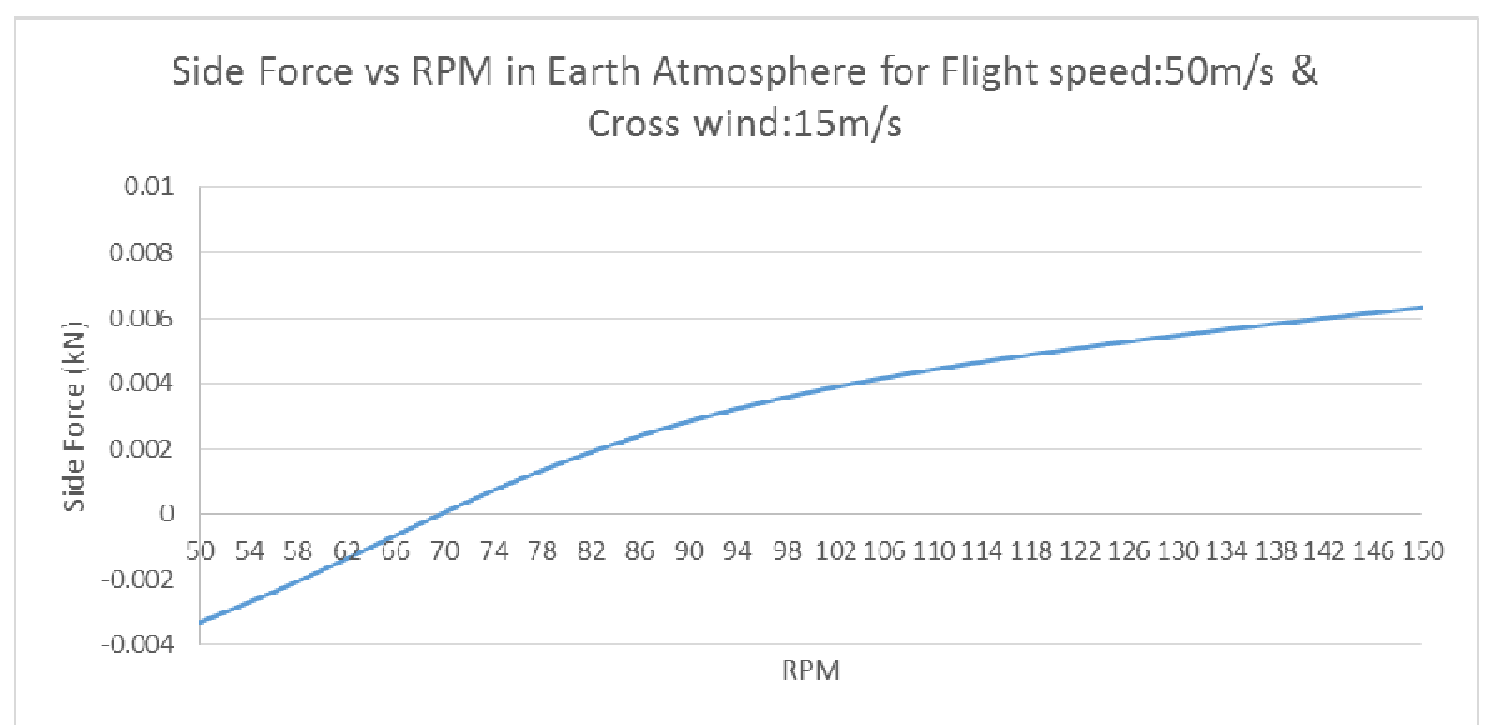

Graph 3: Side Force vs RPM of Final stage rocket in Earth Atmosphere for Flight speed:50m/s \& Cross wind:15m/s

Note: Positive RPM denotes clockwise rotation and Negative RPM denotes Anti-clockwise about positive X-axis. Value ofside force becomes "zero" at RPM 70 (Clockwise) 


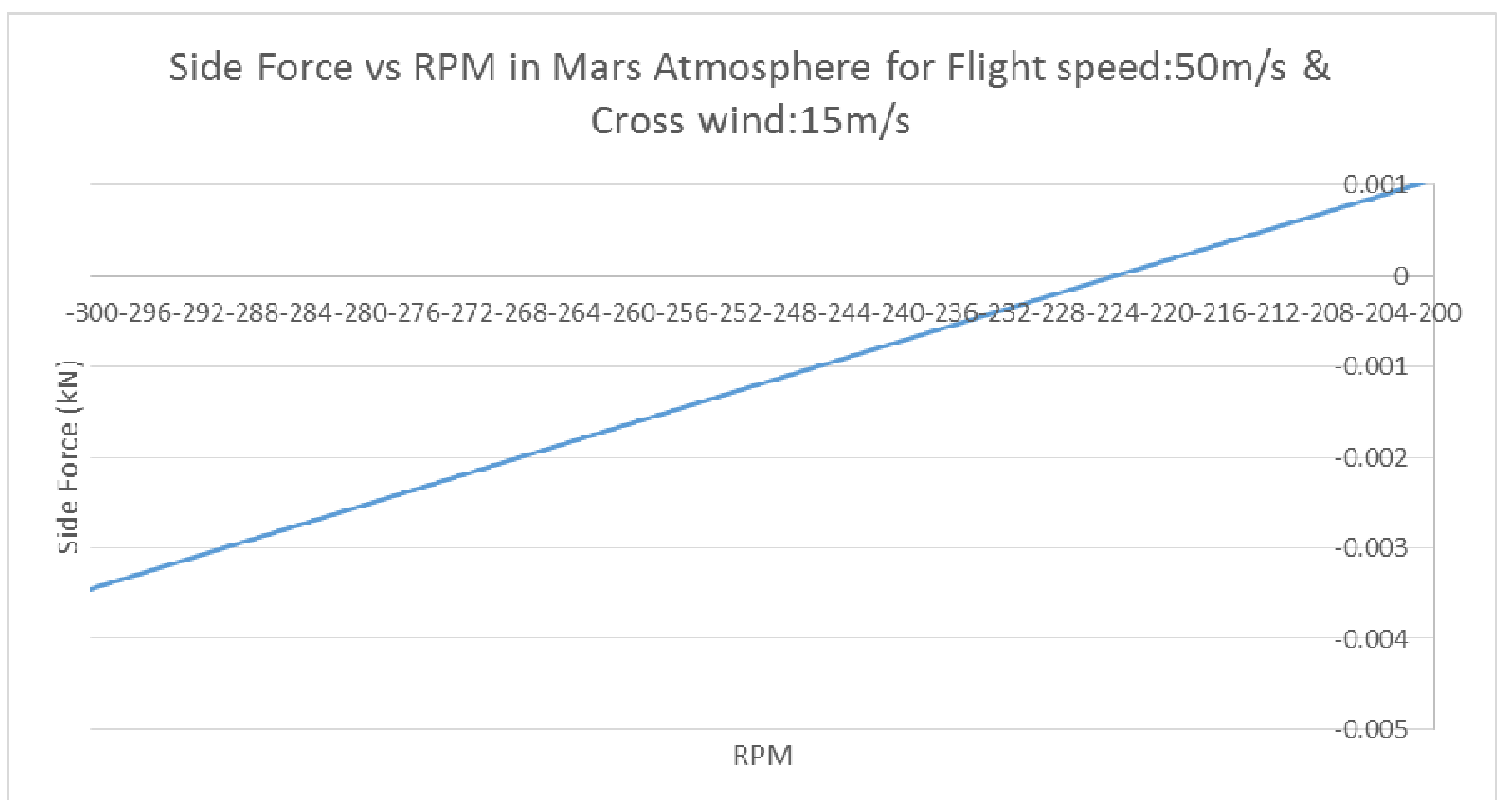

Graph 4: Side Force vs RPM of Final stage rocket in Mars Atmosphere for Flight speed:50m/s \& Cross wind:15m/s

Note: Positive RPM denotes clockwise rotation and Negative RPM denotes Anti-clockwise about positive X-axis. Value of side force becomes "zero" at RPM 224 (Anti-clockwise)

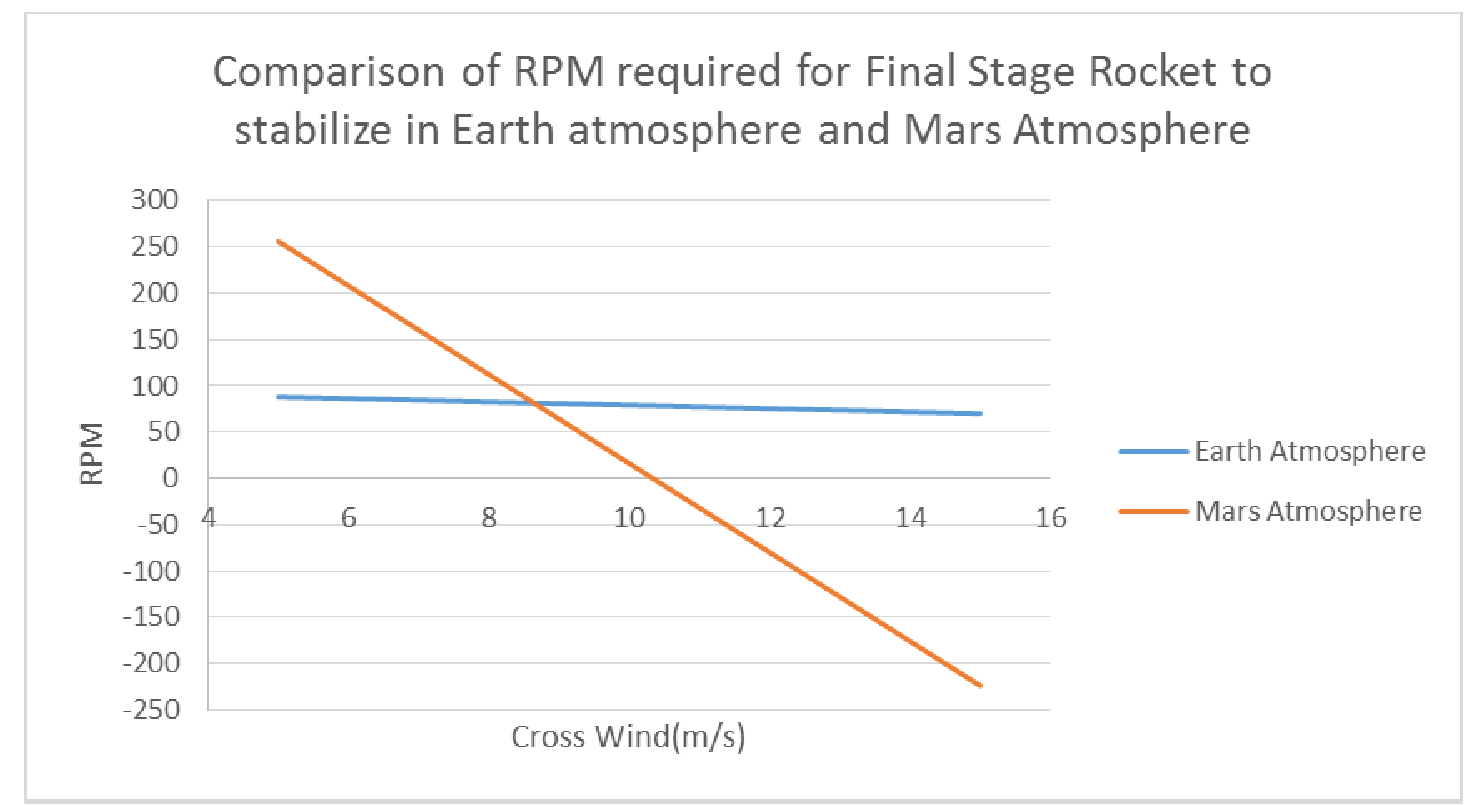

Graph 5: Comparison of RPM required for Final Stage Rocket to stabilize in Earth atmosphere and Mars Atmosphere

\section{DISCUSSIONS}

- $\quad$ Final stage rocket need 88 (Clockwise) RPM to stabilize its flight path in Earth atmosphere. But in Mars, its need 256 (Clockwise) RPM to stabilize its flight path at flight velocity $50 \mathrm{~m} / \mathrm{s}$ and cross wind velocity $5 \mathrm{~m} / \mathrm{s}$

- $\quad$ Final stage rocket need 70 (Clockwise) Rotations per minute to stabilize its flight path in Earth atmosphere. But in Mars, its need 224 (Anti-clockwise) Rotations per minute to stabilize its flight path at flight velocity 50m/s and 
cross wind velocity $15 \mathrm{~m} / \mathrm{s}$.

- The detailed comparison of RPM of Final Stage Rocket in Earth and Mars atmosphere is given in Graph 5

\section{REFERENCES}

1. Lawrence W. Kesting, et al. (1968) Thrust augmentation and spin stabilization mechanism for rocket propelled missiles

2. James I. Crawford, et al. (1983) Spin stabilized impulsively controlled missile

3. Hayden N. Ringer, et al. (1995) Spin-stabilized guided projectile

4. Xu, You Cheng, and Xin Yuan Liu. "Recent progress in double helix conjecture." Int. J. Appl. Nat. Sci 7 (2018): 85-100.

5. MANIKANDAN, S., and AMIT KUMAR THAKUR. "EFFECT OF MAGNUS FORCE ON SPIN STABILIZED MISSILE IN NORMAL CROSSWIND CONDITIONS."International Journal of Mechanical and Production Engineering Research and Development (IJMPERD) 10. 3, Jun 2020, 2965-2974

6. Bhattacharya, S. S., and S. B. Chaudhari. "Study on structural and thermal properties of polypropylene silica nanocomposite filaments." International Journal of Textile and Fashion Technology 5.1 (2015): 15-22.

7. Nikam, Harshal, Prem Mishra, and SayaliBharambe. "Design and Analysis of Brake Rotor with Parameter Optimization." International Journal of Automobile Engineering Research and Development (IJAuERD) 4.4 (2014): 21-30. 

